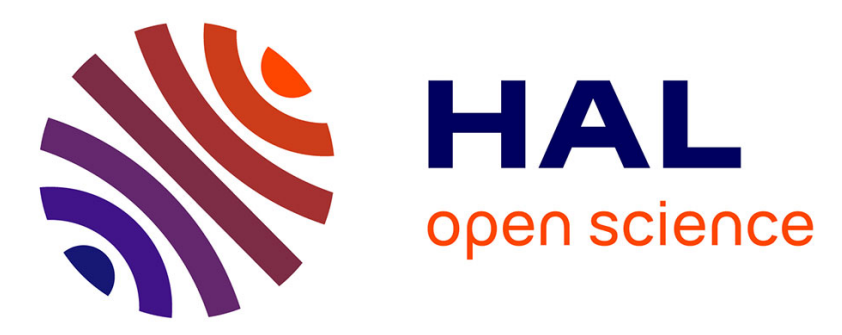

\title{
Role of compositional fluctuations and their suppression on the strain and luminescence of InGaN alloys
}

Konstantinos Pantzas, Gilles Patriarche, David Troadec, Mathieu Kociak, Nikolay Cherkashin, Martin Hÿtch, Julien Barjon, Christian Tanguy, Thomas Rivera, Sundaram Suresh, et al.

\section{To cite this version:}

Konstantinos Pantzas, Gilles Patriarche, David Troadec, Mathieu Kociak, Nikolay Cherkashin, et al.. Role of compositional fluctuations and their suppression on the strain and luminescence of InGaN alloys. Journal of Applied Physics, 2015, 117 (5), pp.55705. 10.1063/1.4907210 . hal-01721149

\author{
HAL Id: hal-01721149 \\ https://hal.science/hal-01721149
}

Submitted on 2 Mar 2018

HAL is a multi-disciplinary open access archive for the deposit and dissemination of scientific research documents, whether they are published or not. The documents may come from teaching and research institutions in France or abroad, or from public or private research centers.
L'archive ouverte pluridisciplinaire HAL, est destinée au dépôt et à la diffusion de documents scientifiques de niveau recherche, publiés ou non, émanant des établissements d'enseignement et de recherche français ou étrangers, des laboratoires publics ou privés. 


\section{Role of compositional fluctuations and their suppression on the strain and luminescence of InGaN alloys}

Konstantinos Pantzas, Gilles Patriarche, David Troadec, Mathieu Kociak, Nikolay Cherkashin, Martin Hÿtch, Julien Barjon, Christian Tanguy, Thomas Rivera, Sundaram Suresh, and Abdallah Ougazzaden

Citation: Journal of Applied Physics 117, 055705 (2015); doi: 10.1063/1.4907210

View online: https://doi.org/10.1063/1.4907210

View Table of Contents: http://aip.scitation.org/toc/jap/117/5

Published by the American Institute of Physics

\section{Articles you may be interested in}

Structural origin of V-defects and correlation with localized excitonic centers in InGaN/GaN multiple quantum wells

Applied Physics Letters 72, 692 (1998); 10.1063/1.120844

Enhanced In incorporation in full InGaN heterostructure grown on relaxed InGaN pseudo-substrate Applied Physics Letters 110, 262103 (2017); 10.1063/1.4989998

Carrier localization in the vicinity of dislocations in InGaN Journal of Applied Physics 121, 013104 (2017); 10.1063/1.4973278

The effect of polarity on MOCVD growth of thick InGaN Applied Physics Letters 110, 022101 (2017); 10.1063/1.4972967

Structural impact on the nanoscale optical properties of InGaN core-shell nanorods Applied Physics Letters 110, 172105 (2017); 10.1063/1.4982594

"S-shaped" temperature-dependent emission shift and carrier dynamics in InGaN/GaN multiple quantum wells Applied Physics Letters 73, 1370 (1998); 10.1063/1.122164

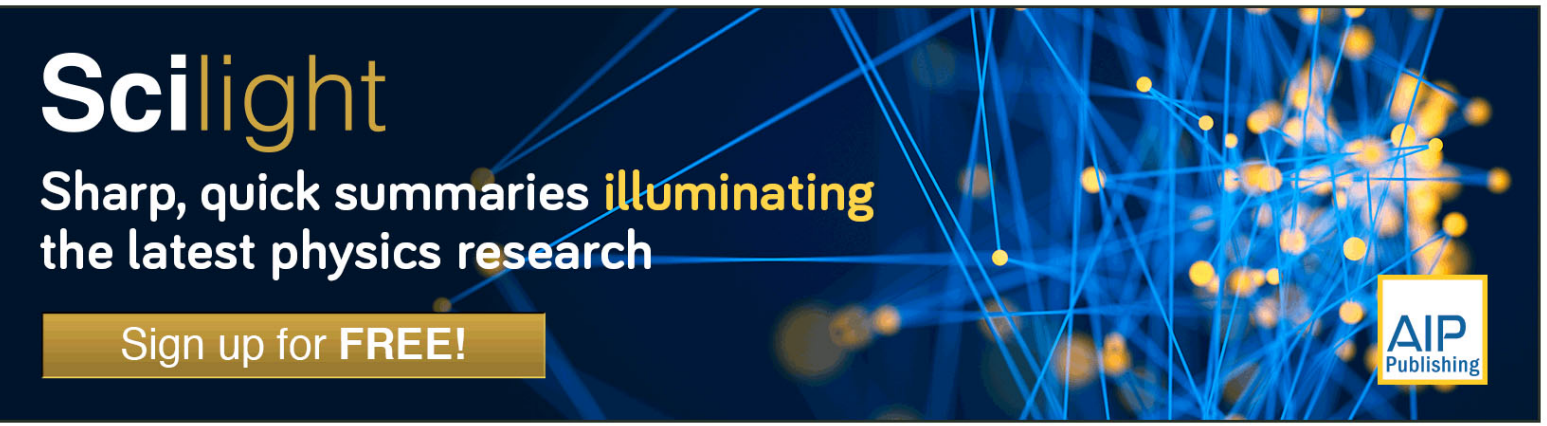




\title{
Role of compositional fluctuations and their suppression on the strain and luminescence of InGaN alloys
}

\author{
Konstantinos Pantzas, ${ }^{1,2,3, a)}$ Gilles Patriarche, ${ }^{3}$ David Troadec, ${ }^{4}$ Mathieu Kociak, ${ }^{5}$ \\ Nikolay Cherkashin, ${ }^{6}$ Martin Hÿtch, ${ }^{6}$ Julien Barjon, ${ }^{7}$ Christian Tanguy, ${ }^{8}$ Thomas Rivera, ${ }^{8}$ \\ Sundaram Suresh, ${ }^{2}$ and Abdallah Ougazzaden ${ }^{1,2}$ \\ ${ }_{1}^{1}$ Georgia Institute of Technology, GT-Lorraine, 2 Rue Marconi, 57070 Metz, France \\ ${ }^{2}$ UMI 2958, Georgia Tech-CNRS, 2 Rue Marconi, 57070 Metz, France \\ ${ }^{3}$ CNRS-LPN, Route de Nozay, F-91460 Marcoussis, France \\ ${ }^{4}$ CNRS, Institut d'Électronique, de Microélectronique \& de Nanotechnologie, UMR 8520, F-59652 Villeneuve \\ D'Ascq, France \\ ${ }^{5}$ Laboratoire de Physique des Solides, Bâtiment 510, CNRS UMR 8502, Université Paris-Sud XI, F-91405 \\ Orsay, France \\ ${ }^{6}$ CEMES-CNRS and Université de Toulouse, 29 rue J. Marvig, 31055 Toulouse, France \\ ${ }^{7}$ Groupe d'Étude de la Matière Condensée, Université de Versailles Saint-Quentin-CNRS, 45 Avenue des \\ États-Unis, Versailles 78035, France \\ ${ }^{8}$ Orange Labs, 40 rue du Général Leclerc, 92794 Issy-les-Moulineaux Cedex 9, France
}

(Received 23 September 2014; accepted 20 January 2015; published online 4 February 2015)

\begin{abstract}
Advanced electron microscopy techniques are combined for the first time to measure the composition, strain, and optical luminescence, of InGaN/GaN multi-layered structures down to the nanometer scale. Compositional fluctuations observed in InGaN epilayers are suppressed in these multi-layered structures up to a thickness of $100 \mathrm{~nm}$ and for an indium composition of $16 \%$. The multi-layered structures remain pseudomorphically accommodated on the GaN substrate and exhibit single-peak, homogeneous luminescence so long as the composition is homogeneous. (C) 2015 AIP Publishing LLC. [http://dx.doi.org/10.1063/1.4907210]
\end{abstract}

\section{INTRODUCTION}

Group-III nitride binary compounds and their alloys span energies between $0.7 \mathrm{eV}$ (indium nitride, InN) and $6.04 \mathrm{eV}$ (aluminum nitride, AIN) with a direct band gap, making them a choice material for a variety of optoelectronic applications in the visible, near, and deep UV regions. Examples of their current applications include white-light emitting diodes (LEDs) for solid-state lighting, and blue laser diodes for high-density optical storage. ${ }^{1-5}$ Photovoltaic energy conversion is another field, where this group of materials shows great promise. ${ }^{6-12}$ Indium gallium nitride ( $\mathrm{InGaN}$ ) alone can match all energies from $0.7 \mathrm{eV}$ to $3.42 \mathrm{eV}$, i.e., more than $80 \%$ of the AM1.5 solar spectrum. ${ }^{13,14}$ Moreover, InGaN alloys have been shown to exhibit very high absorption over the whole composition range, and superior thermal, chemical, and mechanical stability. ${ }^{15}$

Despite such attractive properties, InGaN solar cells have yet to achieve the success of other group-III nitride optoelectronic devices. The difficulty here lies in producing InGaN epilayers that meet the requirements for high-efficiency cells in terms of indium content and epilayer thickness. For instance, for a single-junction cell to achieve maximum conversion efficiency, one would need an InGaN alloy that contains $54 \%$ indium. ${ }^{16,17}$ For a top junction in an ideal twojunction tandem cell with $\mathrm{Si}$, a $46 \%$ InGaN alloy ${ }^{18}$ would be optimal. Finally, in a six multi-junction solar cell, the top cell would require alloys in the range of $10 \%$ to $20 \% .^{19}$ In all cases, and despite the high absorption coefficients reported for

${ }^{a)}$ Electronic mail: konstantinos.pantzas@gatech.edu
InGaN alloys, 100 to $200 \mathrm{~nm}$ of InGaN would be necessary for the full absorption of incident sunlight. ${ }^{20-22}$

Many groups, including the present authors, have reported the growth of InGaN epilayers with indium contents in the range of $30 \%-50 \%$, and thicknesses between $150 \mathrm{~nm}$ and $500 \mathrm{~nm} .^{23-31}$ The reported epilayers, however, invariably suffer from the following issues with respect to material quality: high surface roughness; large compositional fluctuations; high defect densities, presumably caused by strain relaxation. Interestingly enough, depth-resolved studies of these epilayers revealed that the first $20 \mathrm{~nm}$ of growth forms a high-quality sublayer. ${ }^{32}$ Although the average composition is lower than that measured for the subsequent growth of InGaN, this sublayer is compositionally homogeneous. Moreover, the sublayer remains pseudomorphically accommodated on GaN, and thus has no additional structural defects besides those already present in the substrate; finally, it exhibits intense and single-peak optical emission. Promoting the growth of this initial sublayer would therefore be highly desirable, as the resulting epilayer would meet all the requirements for the use of InGaN in solar cells.

Recently, Pantzas et al. $^{33}$ proposed that periodically inserting thin barriers of GaN during InGaN growth could potentially promote the growth of high-quality InGaN. This proposition was based on the assumption that the roughening of the surface of InGaN, compositional fluctuations, and strain relaxation are all linked to the segregation of indium at the surface of the growing film. The barriers are inserted to vent the excess indium accumulated at the surface and reset the growth conditions to those of the initial, high-quality sublayer. This process is referred to as quasi-bulk growth of 

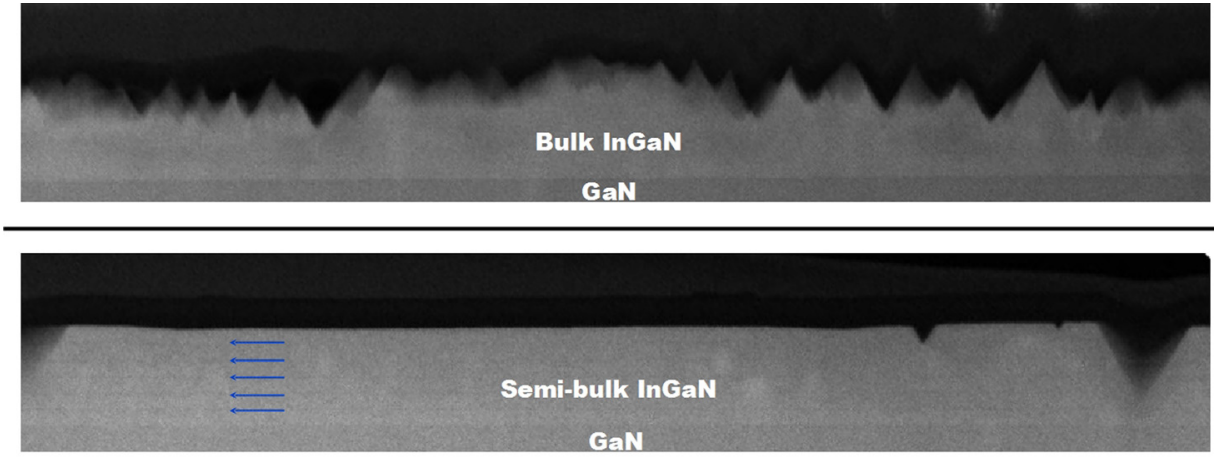

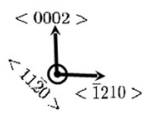

$0.5 \mu \mathrm{m}$
FIG. 1. HAADF-STEM images of the first pair of InGaN epilayers $(x=8 \%)$. The surface of control sample (top) presents a saw-tooth aspect that is completely suppressed in the quasibulk sample (bottom). In this case, five $1.5 \mathrm{~nm}$ thick GaN barriers placed every $20 \mathrm{~nm}$ of InGaN are sufficient.
InGaN (Referred to as semi-bulk growth in Ref. 33). This nomenclature is used to distinguish the present approach from multi-quantum well and superlattice structures. In quasi-bulk InGaN, the objective is to minimize confinement, and efficiently couple the bands of InGaN from one period of the structure to the next. Efficiently coupling the bands is achieved by using the fewest possible GaN barriers and by reducing the thickness of the barriers to the bare minimum required to reset the growth conditions. To minimize confinement, the InGaN well is made as thick as possible. In this sense, charge transport across the structure closely resembles bulk transport in an ideal layer of equivalent InGaN total thickness, hence the name.

An example of the qualitative improvement obtained using quasi-bulk growth is shown in Figure 1. The figure shows high-angle annular dark field scanning transmission electron microscopy (HAADF-STEM) images of a control sample (top), grown without the GaN barriers, and a quasibulk sample (bottom), grown under the same conditions, with the addition of five $1.5 \mathrm{~nm}$ thick GaN barriers. The surface of the control sample exhibits the rough, sawtooth aspect commonly observed for InGaN epilayers grown without the GaN barriers. This surface roughness is completely suppressed in the quasi-bulk sample (bottom) that exhibits smooth, step-flow morphology. The only visible defects are a few V-pits that are known to be linked to emerging threading dislocations of the GaN substrate.
The samples presented in Figure 1 contain only $8 \%$ indium. For epilayers with higher indium contents, excess indium is expected to accumulate more rapidly. Given that the GaN barriers need to be kept as thin as possible to minimize transport losses, one needs to insert GaN barriers more frequently to achieve a similar improvement. Figure 2 compares a control sample against a quasi-bulk sample for which the targeted indium content is $16 \%$. Here, sixteen $1.5 \mathrm{~nm}$ GaN barriers were inserted.

Although the morphology significantly improves using the quasi-bulk growth process, a more in-depth analysis is required to show that the GaN barriers suppress compositional fluctuations and strain relaxation. The present contribution combines advanced transmission electron microscopy techniques to independently measure the composition, deformation, and optical emission of quasi-bulk InGaN, and to discuss the effect of the barriers on the growth and properties of the resulting epilayer. The paper is structured as follows: first, the composition of InGaN epilayers grown both with and without GaN barriers is studied using compositional mappings obtained by quantifying the HAADFSTEM using a few EDX measurements as reference. ${ }^{32}$ Then, Dark-Field Electron Holography ${ }^{34,35}$ is employed to measure the deformation in the InGaN layer at the same location as the one used to obtain the chemical mappings. Finally, the optical luminescence of the InGaN epilayer is studied using cathodoluminescence in a STEM. ${ }^{36}$ The link to results from

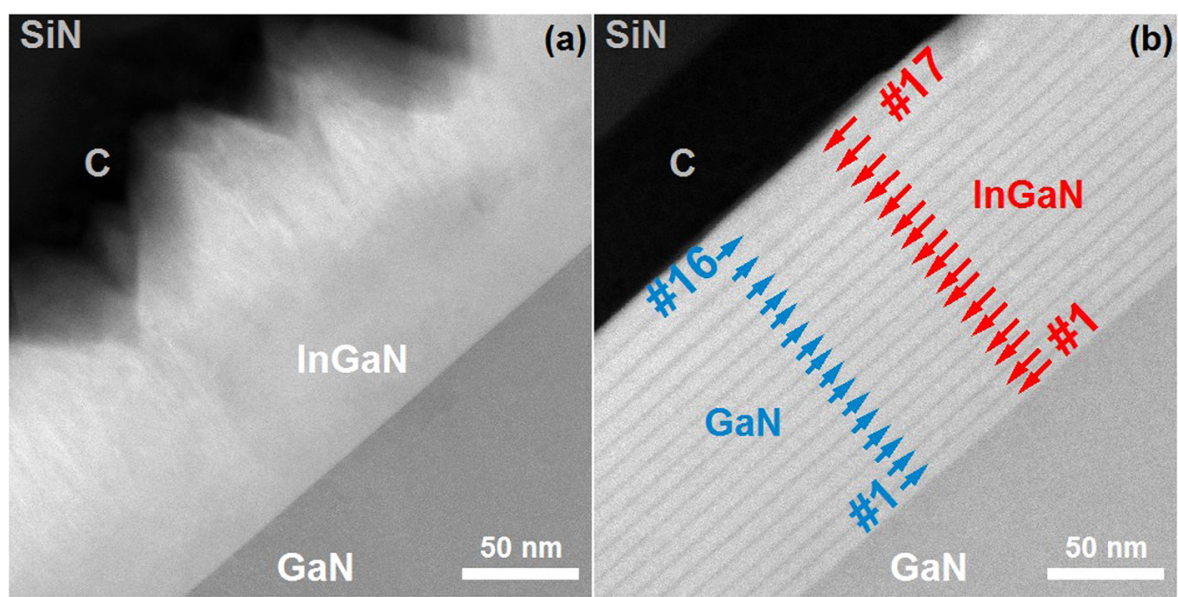

FIG. 2. HAADF-STEM images of a control and quasi-bulk InGaN sample. The control sample (a) exhibits a rough surface as well lateral and vertical variations in the HAADF contrast, which are indicative of compositional fluctuations. Both the roughness and the fluctuations in the contrast have been suppressed in the quasi-bulk epilayer (b), with the insertion of sixteen $1.5 \mathrm{~nm}$ GaN barriers. 
previous sections is made through additional chemical mappings. The ensemble of the experimental data is then discussed and critically analyzed.

\section{EXPERIMENT}

All InGaN films investigated here were grown on $\mathrm{GaN}$ buffered $\mathrm{Al}_{2} \mathrm{O}_{3}$ using metal-organic chemical-vapor deposition (MOCVD). All samples studied come in pairs of an InGaN film grown using the quasi-bulk approach, and the corresponding control sample, grown under identical conditions, but without the GaN barriers. In the first pair, the quasi-bulk sample consists of six, $20 \mathrm{~nm}$ thick layers of InGaN, separated by five, $1.5 \mathrm{~nm}$ thick $\mathrm{GaN}$ barriers. The control sample was a $120 \mathrm{~nm}$ thick InGaN film. The nominal composition for both the quasi-bulk and control InGaN samples was $8 \%$.

In the set of samples discussed in Secs. III A-III C, the quasi-bulk sample consists of seventeen, $8 \mathrm{~nm}$ thick periods of InGaN, separated by sixteen, $2 \mathrm{~nm}$ thick GaN barriers. The control sample is a $136 \mathrm{~nm}$ thick InGaN film. The nominal composition for both the quasi-bulk and control samples is $16 \%$.

Lamellae for observation in a transmission electron microscope were prepared from the samples using focused ion beam (FIB) thinning and ion milling. The lamellae prepared for HAADF STEM, EDX, and electron holography were $80 \mathrm{~nm}$ thick. For the cathodoluminescence experiments, thicker lamellae $(150 \mathrm{~nm})$ had to be prepared to collect sufficient signal in a reasonable amount of time, so as to avoid sample drift during the acquisition.

To preserve the sample surface during FIB preparation, a surface coating consisting of a $50 \mathrm{~nm}$-thick layer of carbon, followed by a $100 \mathrm{~nm}$ layer of $\mathrm{Si}_{3} \mathrm{~N}_{4}$ was applied. Prior to inserting the lamellae in the electron microscope, the lamellae were cleaned using an argon plasma cleaner to remove any residual contamination that may have occurred during transport or storage.

HAADF STEM and energy-dispersive X-ray spectroscopy (EDX) were performed in an aberration-corrected JEOL 2200FS microscope, operating at $200 \mathrm{kV}$ with a probe current of $150 \mathrm{pA}$, and a probe size of $0.12 \mathrm{~nm}$ at the fullwidth at half maximum (FWHM). The convergence halfangle of the probe was $30 \mathrm{mrad}$ and the detection inner and outer half-angles for the HAADF-STEM images were 100 mrad and $170 \mathrm{mrad}$, respectively. The samples were imaged along the $\langle 11 \overline{2} 0\rangle$ zone axis.

Quantitative measurements of the indium composition from EDX were obtained from the intensity ratio of the $\mathrm{L}_{\alpha}$ line of indium $(3.290 \mathrm{keV})$ to the $\mathrm{K}_{\alpha}$ line of gallium $(9.770 \mathrm{keV})$. The $\mathrm{K}$ line of elementary nitrogen $(0.392 \mathrm{keV})$ was also taken into account and revealed that the alloy is stoichiometric. The acquisition time for each EDX spectrum was $60 \mathrm{~s}$, during which no drift in the position of the electron beam was observed. All EDX spectra were acquired using a JEOL 2300D detector and the accompanying JEOL software. The k-factors used by the software had been previously re-calibrated using GaAs, InP, GaN, AlN, GaP, and GaSb, as well as the ternary alloys $\operatorname{In}_{0.48} \mathrm{Al}_{0.52} \mathrm{As}$ and $\operatorname{In}_{0.53} \mathrm{Ga}_{0.47} \mathrm{As}$. These alloys are latticed-matched to InP, allowing the composition to be precisely determined through $\mathrm{X}$-ray diffraction.

The chemical mappings presented throughout this paper were obtained from HAADF and EDX using the method described in Ref. 32. The normalized intensity $\mathcal{I}_{n}$ in HAADF-STEM is linked to the specimen thickness $d$ and the atomic numbers $\mathcal{Z}$ of the atomic column that is being probed through the following equation:

$$
\mathcal{I}_{n}=d\left\langle\mathcal{Z}^{\alpha}\right\rangle .
$$

In the case of an atomic column of InGaN, containing a fraction $x$ of indium $\left(\operatorname{In}_{x} \mathrm{Ga}_{1-x} \mathrm{~N}\right),\left\langle\mathcal{Z}^{\alpha}\right\rangle$ is given by

$$
\left\langle\mathcal{Z}^{\alpha}\right\rangle_{\mathrm{InGaN}}=x \mathcal{Z}_{\mathrm{In}}^{\alpha}+(1-x) \mathcal{Z}_{\mathrm{Ga}}^{\alpha}+\mathcal{Z}_{\mathrm{N}}^{\alpha}
$$

Thus, at any given point in an HAADF STEM image, the composition can be obtained from

$$
x=\frac{\mathcal{Z}_{\mathrm{Ga}}^{\alpha}+\mathcal{Z}_{\mathrm{N}}^{\alpha}}{\mathcal{Z}_{\mathrm{In}}^{\alpha}-\mathcal{Z}_{\mathrm{Ga}}^{\alpha}}\left(\frac{\mathcal{I}_{n}}{d\left(\mathcal{Z}_{\mathrm{Ga}}^{\alpha}+\mathcal{Z}_{\mathrm{N}}^{\alpha}\right)}-1\right) .
$$

Equation (3) contains two unknowns: the thickness $d$ of the STEM lamella and the exponent $\alpha$. STEM lamellae prepared by focused ion beam etching are known to be extremely planar, and a linear two-dimensional fit for $d$ can be readily obtained from a region of constant $\mathcal{Z}$, such as the GaN buffer. The remaining unknown, the scattering exponent $\alpha$, is obtained from a least-squares fit to a set of normalized HAADF intensities, and their corresponding compositions measured at the exact same location using EDX. Typically, a set of 20 EDX measurements is required to obtain a good estimate of $\alpha$. For the chemical mappings presented here, $\alpha \sim 1.7$ was found to be satisfactory.

Dark-field electron holography (DFEH) is a new technique for measuring strain at the nanoscale to high precision and for wide fields of view. ${ }^{34,35} \mathrm{~A}$ diffracted beam emanating from an unstrained region of the sample (the reference area) and from a strained region of the crystal (the measurement area) are interfered with the aid of a bi-prism to form a hologram. The fringe spacing in the reference area is given by the tension on the bi-prism, whilst changes in the fringe spacing that occur in the measurement area can be directly related to the difference in local lattice parameter with respect to the reference area. Thus, the phase of the hologram encodes the information concerning the strain. DFEH experiments were carried out on the Hitachi I2TEMToulouse (in situ interferometry TEM), an HF3300 equipped with cold field-emission gun (CFEG), double stage for aberration-corrected Lorentz microscopy, imaging aberration corrector (CEOS Aplanator), and multiple biprisms. The second specimen stage is located just above the objective lens that can serve as a powerful Lorentz lens coupled to the state-of-the-art aberration corrector. The multiple biprisms allow more flexibility in choosing holographic fringe spacing 
and field of view, and Fresnel fringes can be eliminated. ${ }^{37}$ DFEH holograms were obtained using the (1120) and (0002) diffracted beams. Any additional phase shifts of the beam due to the effect of the microscope optic elements are removed acquiring a reference hologram and subtracting. Geometric phases were obtained with a resolution of $1.5 \mathrm{~nm}$ that corresponds to a $0.75 \mathrm{~nm}$ distance between hologram fringes. Hologram analysis was performed with the software HoloDark 1.2 (HREM Research Inc.) a plug-in for the image processing package DigitalMicrograph 2.3 (Gatan Inc.).

Cathodoluminescence (CL) experiments were performed in a VG-HB 501 STEM working at $60 \mathrm{keV}$ and fitted with an home-made, high efficiency CL detector, as described in Ref. 36. In this technique, an electron beam ( $\varnothing$ $\simeq 1 \mathrm{~nm}$ ) is scanned over the region of interest. At each electron beam position, a CL spectrum is acquired, as well as an $\mathrm{ADF}$ and Bright Field (BF) signal. At the end of the scan, this procedure results in an ADF image, a BF image, and a CL spectral image (SI), i.e., a 3D image with a spectrum per pixel. The three images can then be compared on a pixel by pixel basis. Typical acquisition parameters are $400 \times 400 \mathrm{~nm}$ area, with a $1 \mathrm{~nm} /$ pixel spectral resolution, and a $10 \mathrm{~ms}$ dwell time per pixel. This results in a $655 \mathrm{~s}$ total acquisition time. The experiments performed at approximately $-130^{\circ}$. As the sample drifts during the acquisition of the SI, a posteriori spatial realignment is necessary. The GaN barriers in the sample were used as a reference to realign the SI from the ADF contrast. ${ }^{36}$

\section{RESULTS AND DISCUSSION}

\section{A. Suppression of compositional fluctuations}

Nanometrically resolved mappings of the indium composition are presented in Figure 3. The mappings were obtained by quantifying the contrast of the HAADF-STEM images in Figure 2. The mapping of the control sample (left) reveals that the indium composition has already increased from $16 \%$ to $20 \%$ a mere $20 \mathrm{~nm}$ from the substrate/layer interface. Moreover, lateral fluctuations of the indium composition are observed. The composition can vary laterally from $16 \%$ to $34 \%$ over a few nanometers. Similar findings have been independently reported by a variety of groups, ${ }^{23-31}$ all using different growth conditions, indicating that the presence of both vertical and lateral fluctuations in InGaN alloys is not related to a given set of growth conditions, but is rather an intrinsic phenomenon linked to the growth mechanics of InGaN alloys.

The large lateral fluctuations observed in the control sample are suppressed in the quasi-bulk sample: the composition is found to be laterally homogeneous to within $1 \%$, i.e., the accuracy of the EDX measurement. Vertically, the composition is also found to be homogeneous to within $1.5 \%$. A slight vertical gradient is, however, observed, and the composition increases gradually from $13 \%$ near the substrate/layer interface, to $16 \%$ near the surface. This gradient may be related to the lamella preparation process, as no corresponding gradient in the deformation or luminescence of the epilayer is observed (see Secs. III B and IIIC). The chemical mappings also reveal that the $\mathrm{GaN}$ barriers are, in fact, InGaN barriers ${ }^{50}$ that contain between $5 \%$ indium for the first few barriers and $10 \%$ indium for the barriers near the surface. The TMIn flow is stopped during the barrier growth, the incorporation of indium in the barriers can, therefore, only be attributed to a memory effect in the reactor, or to the buildup of indium that segregates to the surface of the growing layer. Figure 4 shows an atomically resolved HAADF-STEM image of the first the quasi-bulk sample. This image reveals that the transition from InGaN to GaN occurs over a few monolayers (see inset) and is too abrupt to be attributed to a memory effect in the reactor. Thus, a surface segregation of indium is a better explanation for its presence in the barriers. Although unintentional, the incorporation of indium in the barriers also has the added benefit of lowering the barrier height from that of pure $\mathrm{GaN}$, further diminishing potential transport losses in the quasi-bulk layer.

In the vicinity of a V-pit, however, GaN barriers prove to be ineffective, and a transition from two-dimensional to threedimensional growth is observed locally (see Figure 5). Chemical mappings in this region show that the pyramidal tips in this cluster contain up to $34 \% \mathrm{InGaN}$, as is the case for the control sample. Such clusters in InGaN epilayers have been previously reported elsewhere. ${ }^{38-41}$ Cathodoluminescence mappings of their optical emission have revealed a red shift of the emission inside these clusters, in agreement with observed the increase in the concentration. The cluster density is correlated to the density of V-pits ${ }^{40,41}$ that is, in turn, correlated to the density of threading dislocations already present in the

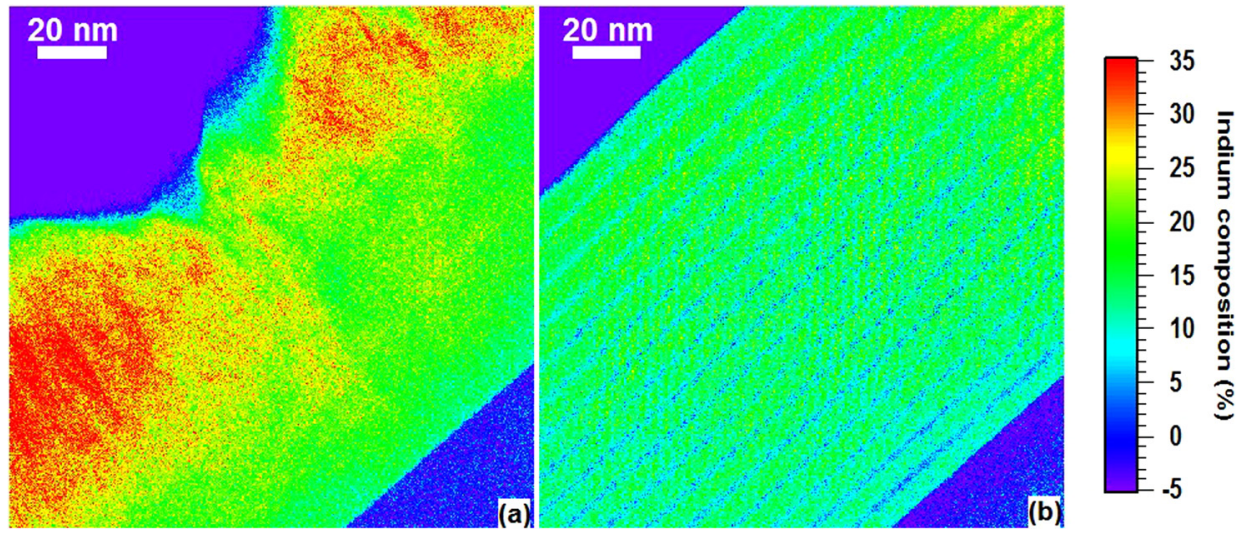

FIG. 3. Nanometrically resolved mappings of the indium composition. The mappings were obtained from the HAADF-STEM images shown in Figure 3. Large compositional fluctuations can be observed in the control sample (a), both along the growth and the in-plane directions. These fluctuations are eliminated in the quasi-bulk sample (b). 


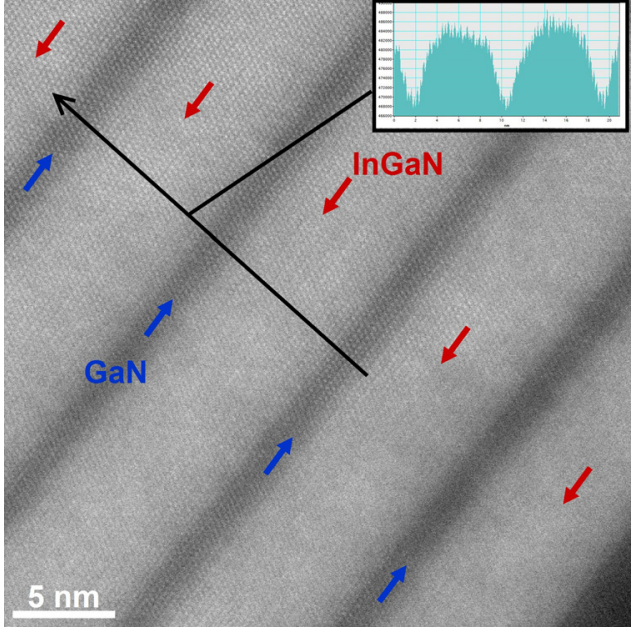

FIG. 4. Atomically resolved HAADF-STEM image spanning the first few periods of the quasi-bulk sample. The interfaces between $\mathrm{GaN}$ and InGaN are abrupt down to a single monolayer, excluding the possibility of indium build-up as a result of a memory effect in the reactor.

substrate. These threading dislocations evidently have a micromasking effect during the growth of the InGaN epilayer, i.e., an effect analogous to that of a mask in selective area growth. An excess of adatoms accumulates in the vicinity of the dislocations, more rapidly than it does far from the dislocations, making the barriers ineffective and triggering the transition to three-dimensional growth. While no such clusters are present in the HAADF-STEM image of the quasi-bulk sample of Figure 1, some clusters can also be observed elsewhere on that sample. Using GaN substrates with lower threadingdislocation densities are expected to reduce the number of clusters, maximizing the potential benefits of the quasi-bulk approach to the growth of InGaN.

Table I summarizes the findings from the chemical mappings presented in this section: it gives the average concentration and the standard deviation at increasing distance from the substrate/layer interface. The standard deviation in the control sample increases to $4 \%$ between $20 \mathrm{~nm}$ and $40 \mathrm{~nm}$ of the substrate/layer interface. In the quasi-bulk, even near a
V-pit, the composition is homogeneous to within the precision of the EDX measurements up to $100 \mathrm{~nm}$.

\section{B. Strain in quasi-bulk InGaN}

The deformation in the quasi-bulk sample was measured independently from the concentration using dark-field electron holography. ${ }^{34}$ In this technique, a diffraction spot and its conjugate are selected from the electron diffraction pattern by means of a bi-prism. The image recorded in TEM camera corresponds to the hologram reconstructed from this one pair of diffraction spots. The geometric phase, from which one can compute the deformation along the crystallographic direction of the selected pair of spots, ${ }^{35}$ is then extracted. By selecting the GaN substrate as a reference, one can then obtain a mapping of the relative deformation in each pixel with respect to $\mathrm{GaN}$ along the selected direction.

The region that was mapped using this technique in the quasi-bulk sample is shown in the HAADF-STEM image shown in Figure 6. This region encompasses the one used to obtain the chemical mappings discussed Sec. III A. Mappings of the deformation along the growth direction, $\Delta c / c$, and along the in-plane direction, $\Delta a / a$, are shown in Figures 6(b) and 6(c), respectively. No deformation is observed along the in-plane direction for the fifteen first periods. Then, the deformation locally increases up to $2 \%$. Along the growth direction, an average deformation of $2 \%$ is measured for the first fifteen periods of quasi-bulk InGaN. This deformation dips to $1.6 \%$ before increasing to $3.5 \%$, as shown in the profile extracted from Figure 6(b) and presented in Figure 7.

Table II compares the deformation measured for each layer against the deformation expected for both a pseudomorphically accommodated and a fully relaxed InGaN lattice. The expected values were computed using the concentrations extracted from the mapping presented previously. The elastic moduli and lattice parameters for GaN and InGaN were taken from Ref. 17. In the pseudomorphic case, the computed deformation was adjusted to accommodate for lamella relaxation, as the thickness of the InGaN epilayer is
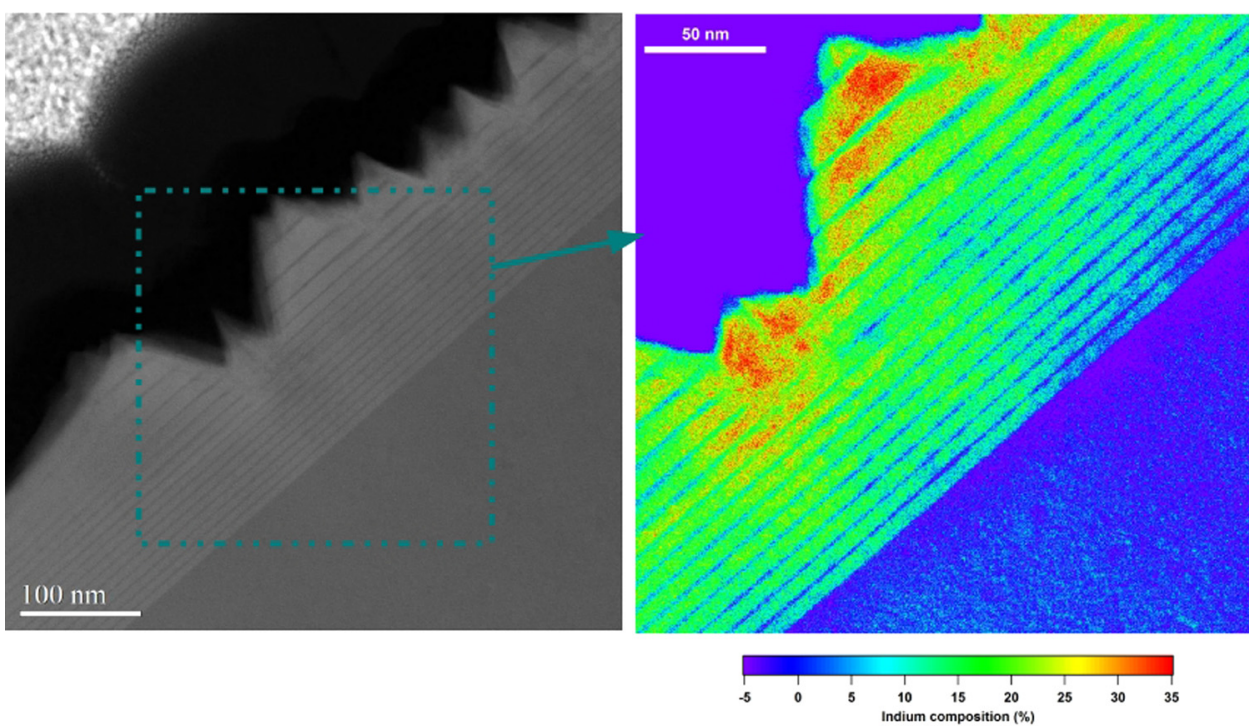

FIG. 5. HAADF-STEM image of the $16 \%$ quasi-bulk sample near a V-pit (left), and corresponding mapping of the indium composition (right). A cluster of $3 \mathrm{D} \mathrm{InGaN}$ appears in the vicinity of the V-pit. The indium concentration in the pyramidal tips of this cluster reaches $34 \%$, the same as in the pyramidal case. 
TABLE I. Average value (avg) and standard deviation (std) of the indium concentration at various distances from the substrate/layer interface in the control sample and the quasi-bulk sample. Large lateral fluctuations of the indium composition appear in the control sample after 20 nm, while the quasi-bulk sample is laterally homogeneous up to $100 \mathrm{~nm}$ from the interface.

\begin{tabular}{|c|c|c|c|c|c|c|}
\hline \multirow{2}{*}{$\begin{array}{l}\text { Distance from } \\
\text { substrate/layer interface }\end{array}$} & \multicolumn{2}{|c|}{ Control sample } & \multicolumn{2}{|c|}{ Quasi-bulk sample } & \multicolumn{2}{|c|}{$\begin{array}{c}\text { Quasi-bulk sample } \\
\text { within } 100 \mathrm{~nm} \text { of V-pit }\end{array}$} \\
\hline & $\begin{array}{l}\text { avg } \\
\text { at. } \%\end{array}$ & $\begin{array}{c}\text { std } \\
\text { at. } \%\end{array}$ & $\begin{array}{l}\text { avg } \\
\text { at. } \%\end{array}$ & $\begin{array}{c}\text { std } \\
\text { at. } \%\end{array}$ & $\begin{array}{l}\text { avg } \\
\text { at. } \%\end{array}$ & $\begin{array}{l}\text { std } \\
\text { at. } \%\end{array}$ \\
\hline 20 & 15.86 & 0.86 & 12.5 & 1 & 14.65 & 0.9 \\
\hline 40 & 16.68 & 3.26 & 13.11 & 0.75 & 14.68 & 0.75 \\
\hline 80 & 28.9 & 3.6 & 15.56 & 1.1 & 15.53 & 0.8 \\
\hline 100 & 29.96 & 4 & 16.10 & 1 & 14.12 & 1.6 \\
\hline
\end{tabular}
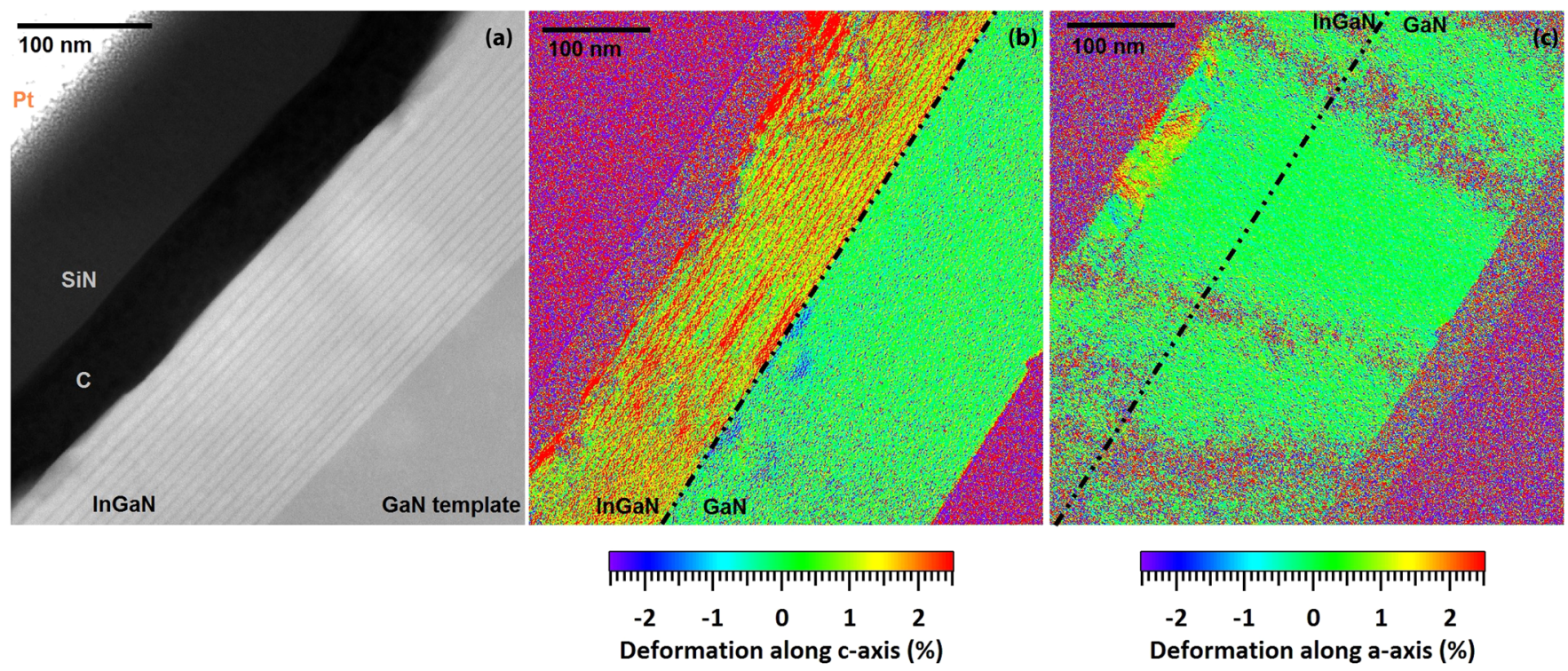

FIG. 6. Nanometrically resolved mappings of the deformation in the quasi-bulk sample. (a) HAADF-STEM image of the area, where the deformation was measured in the quasi-bulk sample. (b) Mapping of the deformation along $\langle 0002\rangle(\Delta c / c)$. (c) Mapping of the deformation along $\langle 1 \overline{1} 00\rangle(\Delta a / a)$. The observed values for the deformation are consistent with a $16 \% \mathrm{InGaN}$ alloy that is pseudomorphically strained on the underlying GaN template.

of the same order of magnitude as the lamella thickness. Over the first fifteen periods, the measured data are in good agreement with the pseudomorphic case. This is the case even in the vicinity of a V-pit (see Figure 8). The dip and

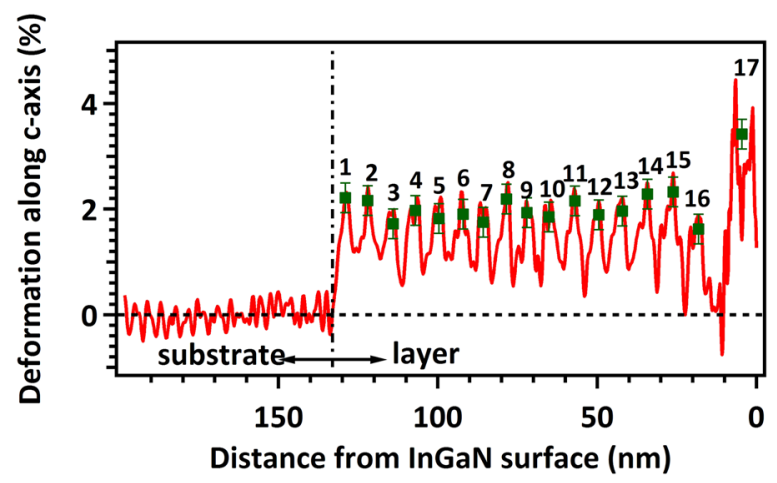

FIG. 7. Profile of $\Delta c / c$ extracted from the mapping in Figure 6. An average deformation of $2 \%$ can be measured for the first fifteen periods. This value increases to $3.5 \%$ over the last two periods. Given the concentrations measured at the same locations previously, these values are in good agreement with the deformation expected for an InGaN lattice pseudomorphically strained on GaN. subsequent increase of the deformation along the c-axis, observed over the last two periods of the sample, may indicate a partial relaxation of the InGaN lattice. This may, however, also be an artifact of the experiment, as the deformation along the in-plane direction does not show a trend consistent with a partial relaxation. The average deformation for the first fifteen periods, $2 \%$, corresponds to an average composition of $14 \%$. Given the error margin, this finding is in good agreement with the composition obtained from the chemical mappings in the same region. Furthermore, these results (pseudomorphic accommodation, total deformation along the c-axis of $2 \%$ ) are in excellent agreement with findings from reciprocal space mappings of the asymmetric $11 \overline{2} 4$ reflection, shown in Figure 9. This confirms that, despite the local character of the measurements presented here, the findings accurately reflect the macroscopic properties of the quasi-bulk sample.

Even though the InGaN epilayer is partially relaxed over the last two periods, the initial fifteen periods represent a total thickness of approximately $100 \mathrm{~nm}$ of pseudomorphically accommodated InGaN. This is an improvement by more than an order of magnitude of what is expected for InGaN according to the most recent model proposed in the 
TABLE II. Measured and expected deformations along the c-axis. The expected deformation was computed using the concentrations determined from the chemical mapping of the quasi-bulk sample presented in Figure 3. For the first fifteen periods, the measured deformation corresponds to the deformation expected in the case of a pseudomorphically accommodated InGaN epilayer. The last two periods appear to partially relax.

\begin{tabular}{lcccc}
\hline \hline & & \multicolumn{3}{c}{ Deformation along c-axis } \\
\cline { 3 - 5 } & & & expected & $\begin{array}{c}\text { expected } \\
\text { relaxed } \\
\text { Period }\end{array}$ \\
\cline { 3 - 5 }$\#$ & $\begin{array}{c}\text { Composition } \\
\text { at. \% }\end{array}$ & $\begin{array}{c}\text { measured } \\
\text { \%seudomorphic }\end{array}$ & $\%$ & 1.05 \\
\hline 1 & 10.50 & 2.21 & 1.72 & 1.13 \\
2 & 11.30 & 2.16 & 1.77 & 1.25 \\
3 & 12.50 & 1.72 & 1.88 & 1.33 \\
4 & 13.35 & 1.97 & 1.94 & 1.34 \\
5 & 13.40 & 1.82 & 1.96 & 1.34 \\
6 & 13.40 & 1.90 & 1.96 & 1.39 \\
7 & 13.90 & 1.75 & 2.00 & 1.40 \\
8 & 14.00 & 2.19 & 2.01 & 1.42 \\
9 & 14.24 & 1.93 & 2.03 & 1.43 \\
10 & 14.27 & 1.85 & 2.03 & 1.48 \\
11 & 14.79 & 2.15 & 2.08 & 1.50 \\
12 & 15.03 & 1.89 & 2.09 & 1.55 \\
13 & 15.55 & 1.96 & 2.13 & 1.61 \\
14 & 16.12 & 2.28 & 2.18 & 1.66 \\
15 & 16.60 & 2.32 & 2.22 & 1.63 \\
16 & 16.30 & 1.62 & 2.20 & \\
17 & 13.25 & 3.42 & 1.95 & \\
\hline \hline & & & & \\
\hline
\end{tabular}

literature $^{42}$ that predicts a critical thickness for plastic relaxation of no more than $8 \mathrm{~nm}$ for a layer that contains $15 \%$ indium. This observation, along with the observations made both by this group and others that show the presence of both relaxed and strained components in $\mathrm{InGaN}$ epilayers grown without the quasi-bulk process, ${ }^{24,29-32}$ tends to confirm that the preferred method of strain relaxation in InGaN alloys is a transition from two-dimensional to three-dimensional growth, rather than a relaxation through the generation of misfit dislocations. A similar conclusion was drawn in Ref. 43. The study presented therein is based on XRD and AFM measurements on a macroscopic level, highlighting again

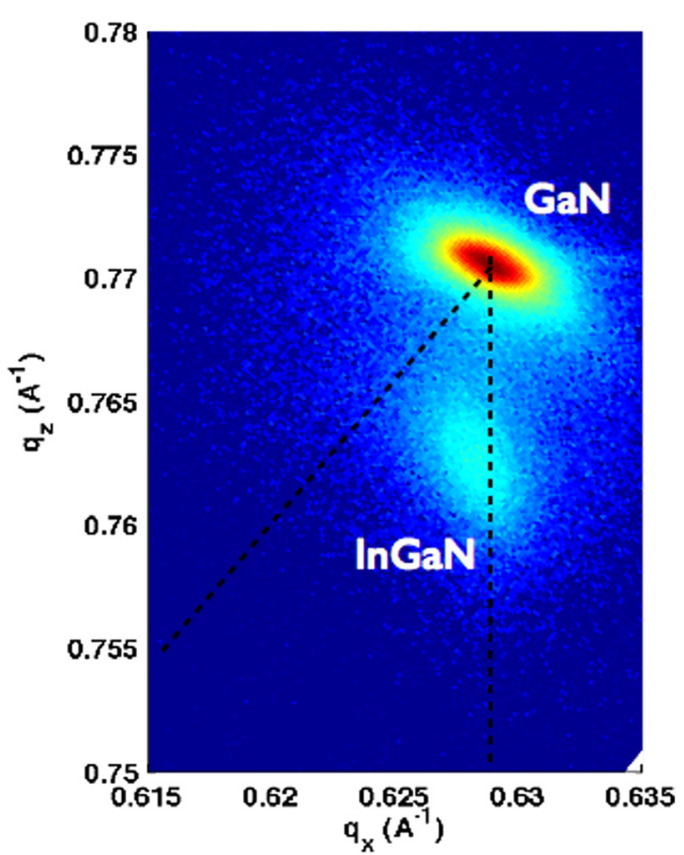

FIG. 9. Reciprocal space mapping of the $11 \overline{2} 4$ asymmetric reflexion of in the quasi-bulk sample, obtained from X-ray diffraction. The intense spot corresponds to diffraction from the substrate. A spot situated directly below it comes from diffraction of the quasi-bulk InGaN epilayer. This mapping confirms that, macroscopically, the quasi-bulk InGaN epilayer is pseudomorphically accommodated on the substrate. Furthermore, the deformation extracted for the InGaN epilayer is in excellent agreement with the one measured from the HoloDark mappings.

that the findings from the microscopic analysis presented here accurately reflects macroscopic properties of InGaN epilayers.

\section{Nanometrically resolved optical emission in quasi-bulk InGaN}

The optical emission of the quasi-bulk InGaN sample was studied using cathodoluminescence in a STEM. In contrast to traditional cathodoluminescence and photoluminescence, the spatial resolution of this technique is not limited by the interaction volume, which is nanometric given the
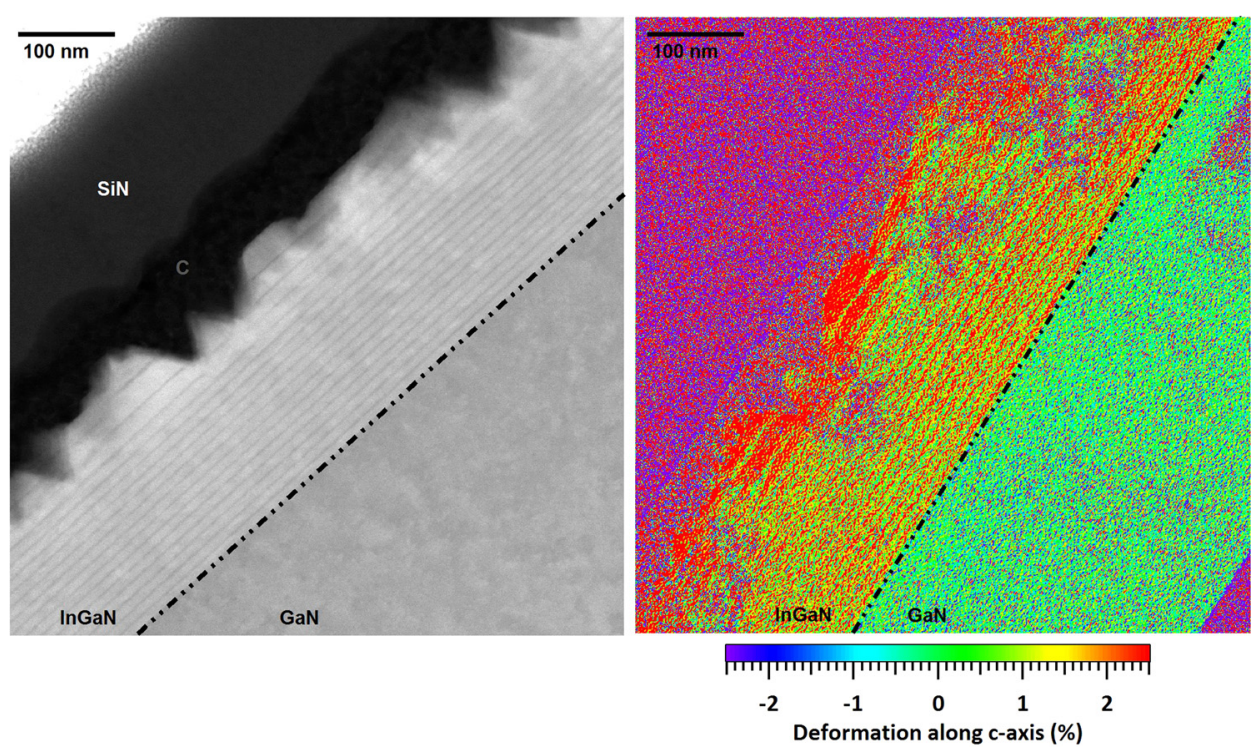

FIG. 8. (Left) HAADF-STEM image of a zone in the vicinity of V-pit. (Right) Mapping of the deformation along the growth direction. The deformation uniformly increases over the last two periods from $2 \%$ to $3.5 \%$. Both values are consistent with what is expected for a pseudomorphic accommodation of the InGaN lattice on the GaN substrate, given the concentrations measured previously. 


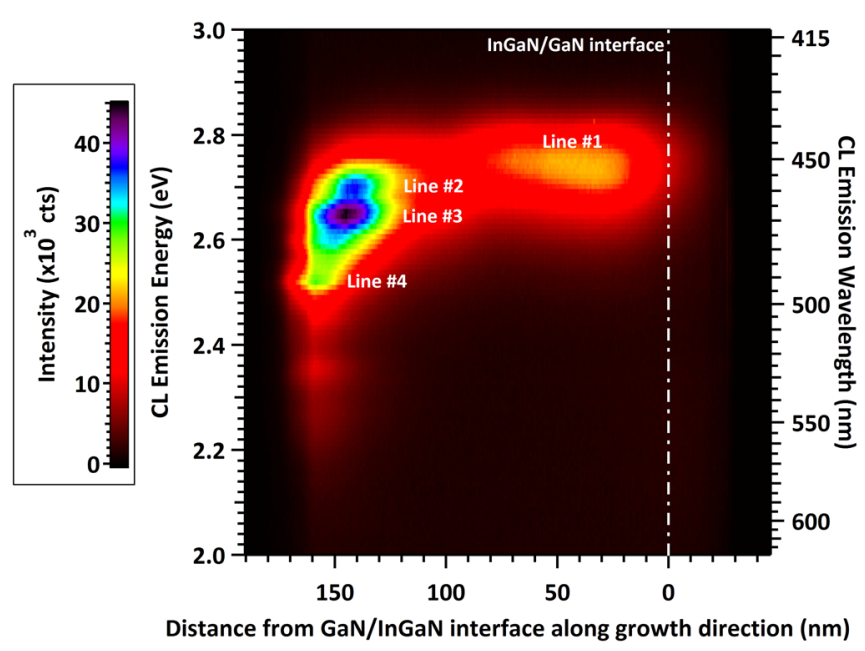

FIG. 10. Nanometrically resolved optical emission in the quasi-bulk sample acquired, using STEM-CL. The projection of the spectral image represented here is obtained by integrating the spectral image along the in-plane direction of the sample. At least four distinct emission lines can be identified in this projection. Only one of them is present for the first fourteen periods of quasi-bulk InGaN, while the other three appears near the sample surface.

acceleration voltage and the relative thinness of the TEM lamella. The spatial resolution in this case is given by the diffusion length of electrons in the material. Given the short diffusion lengths reported for III-nitrides, ${ }^{44}$ the spatial resolution is expected to be less than $50 \mathrm{~nm}$.

To identify the emissions present in the quasi-bulk sample, the intensity of the spectral image was integrated along the in-plane direction. The projection obtained in this manner is shown in Figure 10, and four distinct emission lines are found in the sample. The emission line energies, taken at the inflexion point on the low-energy side of the emission line, are summarized in Table III. Emission line \#1 is present throughout the first fourteen periods of the quasi-bulk sample. The intensity is homogeneously distributed over ten of those; then, dips down as carriers are injected in the last three periods, where the concentration is higher according to the chemical mapping. Emission lines \#2 through \#4, on the other hand, are confined to regions of the last few layers.

Energy-filtered images that map the intensity distribution of the identified emission lines are presented in Figure 11, alongside a chemical mapping of the same region.

TABLE III. Band-gap energies associated to the emission lines identified in Fig. 10. The energies where taken at the inflexion point on the low-energy side of the emission lines. The composition measured in the region the emission lines is also given, as well as the expected band-gap energy for bulk, strain-free InGaN.

\begin{tabular}{lcccc}
\hline \hline $\begin{array}{l}\text { Emission } \\
\text { Line } \\
(\#)\end{array}$ & $\begin{array}{c}\text { Energy } \\
(\mathrm{eV})\end{array}$ & $\begin{array}{c}\text { Wavelength } \\
(\mathrm{nm})\end{array}$ & $\begin{array}{c}\text { Composition } \\
\text { (from mapping) } \\
(\text { at. } \%)\end{array}$ & $\begin{array}{c}\text { Expected band-gap } \\
\text { energy }^{\mathrm{a}} \\
(\mathrm{eV})\end{array}$ \\
\hline 1 & 2.66 & 466 & 15 & 2.84 \\
2 & 2.64 & 470 & 20 & 2.65 \\
3 & 2.59 & 479 & 23 & 2.55 \\
4 & 2.54 & 488 & 24 & 2.52 \\
\hline \hline
\end{tabular}

aThe band-gap energy is that computed for bulk, strain-free InGaN at the same composition as that reported in the table. See text for details.
Linking the composition to the energies reported in Table III is not straightforward, because of many effects: reduced dimensionality, strain, piezoelectric and spontaneous polarization, possible carrier screening, and excitonic effects. Even though accurate measurements of the thickness, composition, and strain in the individual $\mathrm{InGaN}$ wells and $\mathrm{GaN}$ barriers are available in the present study, several values of basic parameters such as the band offsets between InGaN and $\mathrm{GaN}$, are not well known or controversial ${ }^{17}$ to provide an accurate estimation of the band structure.

Nonetheless, several observations can be made by comparing the energy-filtered images to the chemical mapping. First, emission lines \#3 and \#4 can be ascribed to the cluster of higher indium composition located in the bottom-left corner of the chemical mapping. The presence of such clusters has been previously proposed as the origin of the bright luminescence of InGaN alloys. ${ }^{44}$ A few groups have claimed that such clusters form during the TEM observation of InGaN samples. ${ }^{45}$ Recently, however, using careful sample preparation and observing the specimen in a scanning transmission electron microscope, Rosenauer et al. ${ }^{46}$ showed that such clusters do exist in InGaN wells. Figure 11 confirms that indium-rich clusters do indeed strongly contribute to the luminescence of InGaN: emission line \#3 is the strongest emission observed in the sample according to Figure 10.

The clusters are not, however, the only source of emission in this region of the sample. They exist alongside emission line \#2 that is homogeneously distributed over layers \#15, \#16, and \#17. The red-shift of this emission with respect to emission line \#1 can be ascribed to an increase in the average indium concentration from $15 \%$ to $20 \%$, as observed in the chemical mapping.

Emission line \#1 is located in a region, where the quasibulk layer is fully strained and has a laterally homogeneous composition for over $100 \mathrm{~nm}$. A meaningful comparison can therefore be made with bulk, strain-free InGaN. Indeed, in contrast to other works, ${ }^{8,10-12}$ the InGaN wells in the present work are not isolated, as the barriers are very thin and relatively low (see also Ref. 50). Thus, electron wave-functions are expected to extend over several successive layers. The band-gap energy of bulk, strain-free InGaN is taken from the usual

$$
E_{\mathrm{InGaN}}(x)=x E_{\mathrm{InN}}+(1-x) E_{\mathrm{GaN}}+b x(1-x) .
$$

Values for the end-point binary band-gap energies and the bowing parameter $b$ were taken from Ref. 17. According to the chemical mapping, the composition in this region of the quasi-bulk sample is $15 \%$, which yields a net red-shift of $140 \mathrm{meV}$. This red-shift is in good agreement with results previously published in the literature. ${ }^{47-49}$

\section{CONCLUSION}

In light of the results presented in Secs. II-III, it becomes apparent that the multi-layered InGaN/GaN structures discussed here do indeed exhibit a behavior similar to that of an ideal bulk InGaN epilayer. Despite the complexity of the band structure expected for such InGaN/GaN stacks, quasi-bulk InGaN exhibits homogeneous, intense, and 


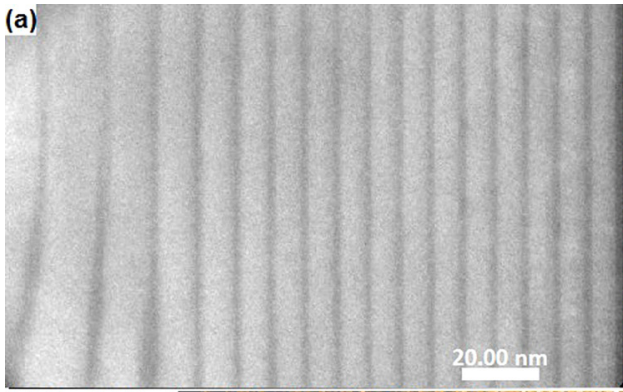

(c) $\mathrm{E}=2.76 \mathrm{eV}$

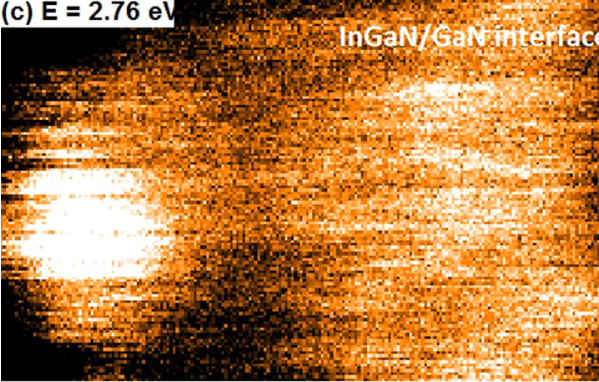

(e) $\mathrm{E}=2.66 \mathrm{eV}$
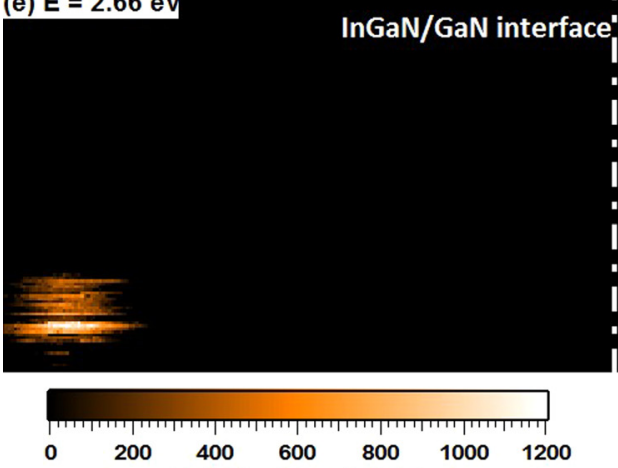

Emission Intensity (cts)

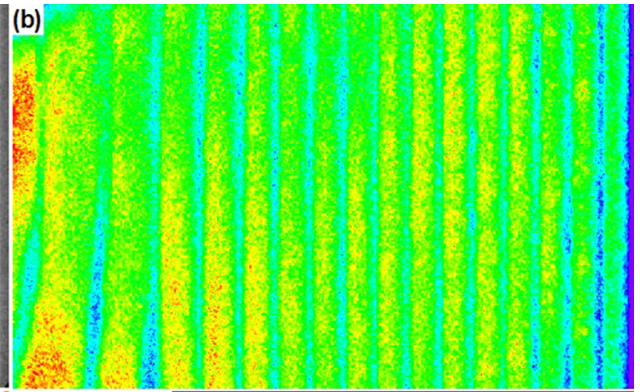

(d) $E=2.7 \mathrm{eV}$

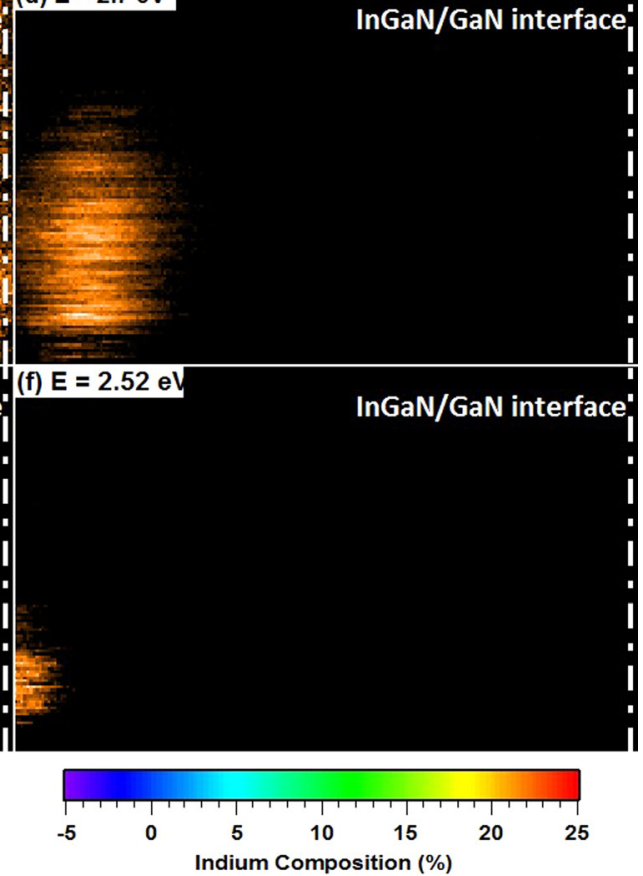

FIG. 11. Optical emission compared against the distribution of indium in the quasi-bulk sample. (a) HAADFSTEM image of the mapped region; (b) corresponding mapping of the indium composition; (c)-(f) energy filtered CL images, centered at the peak of the four emission lines identified in Figure 11. Emission line \#1 is the only emission present during the first fourteen periods of the quasi-bulk structure, while emission lines \#2 through \#4 are confined to the surface of the sample, where they coincide with local increases of the indium composition. single-peak luminescence for at least $100 \mathrm{~nm}$. The GaN barriers do not appear to significantly hinder carrier transport across the structure, indicating that such structures can be used in solar cells without significant electrical losses. Furthermore, despite the high average indium content, strain in the structure is not relaxed until the last $20 \mathrm{~nm}$ of the InGaN/GaN stack, preserving the crystalline quality of the material. Strain in the structure is shown to reduce the band gap, pushing it even further in the visible region of the solar spectrum, thus potentially increasing the efficiency of quasibulk InGaN-based solar cells. The comparison with control samples grown without GaN barriers confirms that it is the suppression of short-range compositional fluctuations that is indeed the source of improvement. Although a vertical gradient of composition may still be present, both strain and optical emission in the quasi-bulk structure do not appear to be adversely affected by it. Threading dislocations present in the GaN/Sapphire template currently limit the improvement that can be obtained by using such structures, and the use of ultra-low dislocation-density GaN substrates is expected to yield even better results.

\section{ACKNOWLEDGMENTS}

This work was supported by ANR project NewPVonGlass. The authors also acknowledge support from the French Renatech network of the CNRS, as well as financial support from the French CNRS (FR3507) and CEA METSA network (www.metsa.fr).

${ }^{1}$ S. Nakamura, S. Pearton, and G. Fasol, The Blue Laser Diode: The Complete Story (Springer, 2000).

${ }^{2}$ J. Orton and C. Foxon, Rep. Prog. Phys. 61, 1 (1998).

${ }^{3}$ M. R. Krames, O. B. Shchekin, R. Mueller-Mach, G. O. Mueller, L. Zhou, G. Harbers, and M. G. Craford, J. Disp. Technol. 3, 160 (2007).

${ }^{4}$ S. Nakamura, Solid State Commun. 102, 237 (1997).

${ }^{5}$ K. Ohkawa, T. Watanabe, M. Sakamoto, A. Hirako, and M. Deura, J. Cryst. Growth 343, 13 (2012).

${ }^{6}$ O. Jani, I. Ferguson, C. Honsberg, and S. Kurtz, Appl. Phys. Lett. 91, 132117 (2007).

${ }^{7}$ C. Neufeld, N. Toledo, S. Cruz, M. Iza, S. Denbaars, and U. Mishra, Appl. Phys. Lett. 93, 143502 (2008).

${ }^{8}$ R. Dahal, B. Pantha, J. Li, J. Y. Lin, and H. X. Jiang, Appl. Phys. Lett. 94, 063505 (2009).

${ }^{9}$ X.-M. Cai, S.-W. Zeng, and B.-P. Zhang, Appl. Phys. Lett. 95, 173504 (2009).

${ }^{10}$ R. Dahal, J. Li, K. Aryal, J. Y. Lin, and H. X. Jiang, Appl. Phys. Lett. 97, 073115 (2010).

${ }^{11}$ E. Matioli, C. Neufeld, M. Iza, S. C. Cruz, A. A. Al-Heji, X. Chen, R. M. Farrell, S. Keller, S. Denbaars, U. Mishra, S. Nakamura, J. Speck, and C. Weisbuch, Appl. Phys. Lett. 98, 021102 (2011).

${ }^{12}$ J. Lang, C. Neufeld, C. A. Hurni, S. Cruz, E. Matioli, U. Mishra, and J. Speck, Appl. Phys. Lett. 98, 131115 (2011).

${ }^{13}$ J. Wu, W. Walukiewicz, K. M. Yu, J. W. Ager III, E. E. Haller, H. Lu, W. J. Schaff, Y. Saito, and Y. Nanishi, Appl. Phys. Lett. 80, 3967 (2002).

${ }^{14}$ V. Davydov, A. Klochikhin, R. Seisyan, V. Emtsev, S. Ivanov, F. Bechstedt, J. Furthmuller, H. Harima, A. Mudryi, J. Aderhold, O. Semchinova, and J. Graul, Phys. Status Solidi B 229, R1 (2002).

${ }^{15}$ J. Wu, W. Walukiewicz, K. M. Yu, W. Shan, J. W. Ager III, E. E. Haller, H. Lu, W. J. Schaff, W. K. Metzger, and S. Kurtz, J. Appl. Phys. 94, 6477 (2003). 
${ }^{16}$ T. Markvart and L. Castaner, Practical Handbook of Photovoltaics, Fundamentals and Applications (Elsevier, 2003).

${ }^{17}$ I. Vurgaftman and J. R. Meyer, J. Appl. Phys. 94, 3675 (2003).

${ }^{18}$ L. Hsu and W. Walukiewicz, J. Appl. Phys. 104, 024507 (2008).

${ }^{19}$ H. Hamzaoui, A. Bouazzi, and B. Rezig, Sol. Energy Mater. Sol. Cells 87, 595 (2005); International Conference on Physics, Chemistry and Engineering of Solar Cells, Badajoz, Spain, 13-15 May 2004.

${ }^{20}$ J. Wu, W. Walukiewicz, K. M. Yu, J. W. Ager III, E. E. Haller, H. Lu, and W. J. Schaff, Appl. Phys. Lett. 80, 4741 (2002).

${ }^{21}$ M. Hori, K. Kano, T. Yamaguchi, Y. Saito, T. Araki, Y. Nanishi, N. Teraguchi, and A. Suzuki, Phys. Status Solidi B 234, 750 (2002).

${ }^{22}$ O. Jani, "Development of wide-band gap InGaN solar cells for highefficiency photovoltaics," Ph.D. thesis (Georgia Institute of Technology, 2008)

${ }^{23}$ S. Pereira, M. R. Correia, E. Pereira, K. P. O’Donnell, C. Trager-Cowan, F. Sweeney, E. Alves, A. D. Sequeira, N. Franco, and I. M. Watson, Phys. Status Solidi B 228, 59 (2001).

${ }^{24}$ S. Pereira, M. R. Correia, E. Pereira, K. P. O’Donnell, E. Alves, A. D. Sequeira, and N. Franco, Appl. Phys. Lett. 79, 1432 (2001).

${ }^{25}$ S. Pereira, M. R. Correia, E. Pereira, K. P. O'Donnell, C. Trager-Cowan, F. Sweeney, and E. Alves, Phys. Rev. B 64, 205311 (2001).

${ }^{26}$ S. Pereira, M. R. Correia, T. Monteiro, E. Pereira, E. Alves, A. D. Sequeira, and N. Franco, Appl. Phys. Lett. 78, 2137 (2001).

${ }^{27}$ S. Pereira, M. R. Correia, E. Pereira, K. P. O’Donnell, E. Alves, A. D. Sequeira, N. Franco, I. M. Watson, and C. J. Deatcher, Appl. Phys. Lett. 80, 3913 (2002).

${ }^{28}$ S. Pereira, M. R. Correia, E. Pereira, C. Trager-Cowan, F. Sweeney, K. P. O’Donnell, E. Alves, N. Franco, and A. D. Sequeira, Appl. Phys. Lett. 81, 1207 (2002).

${ }^{29}$ L. Sang, M. Takeguchi, W. Lee, Y. Nakayama, M. Lozac'h, T. Sekiguchi, and M. Sumiya, Appl. Phys. Express 3, 111004 (2010).

${ }^{30}$ H. Wang, D. Jiang, U. Jahn, J. Zhu, D. G. Zhao, Z. Liu, S. Zhang, and H. Yang, Thin Solid Films 518, 5028 (2010).

${ }^{31}$ Z. Liliental-Weber, K. M. Yu, M. Hawkridge, S. Bedair, A. E. Berman, A. Emara, J. Domagala, and J. Bak-Misiuk, Phys. Status Solidi C 6, S433 (2009).

${ }^{32}$ K. Pantzas, G. Patriarche, D. Troadec, S. Gautier, T. Moudakir, S. Suresh, L. Largeau, O. Mauguin, P. L. Voss, and A. Ougazzaden, Nanotechnology 23, 455707 (2012).

${ }^{33}$ K. Pantzas, Y. E. Gmili, J. Dickerson, S. Gautier, L. Largeau, O. Mauguin, G. Patriarche, S. Suresh, T. Moudakir, C. Bishop, A. Ahaitouf, T. Rivera, C. Tanguy, P. Voss, and A. Ougazzaden, J. Cryst. Growth 370, 57 (2013).
${ }^{34}$ M. Hýtch, F. Houdellier, F. Hue, and E. Snoeck, Nature 453, 1086 (2008).

${ }^{35}$ M. Hýtch, F. Houdellier, F. Hue, and E. Snoeck, Ultramicroscopy 111, 1328 (2011).

${ }^{36}$ L. F. Zagonel, S. Mazzucco, M. Tence, K. March, R. Bernard, B. Laslier, G. Jacopin, M. Tchernycheva, L. Rigutti, F. H. Julien, R. Songmuang, and M. Kociak, Nano Lett. 11, 568 (2011).

${ }^{37}$ K. Harada, A. Tonomura, Y. Togawa, T. Akashi, and T. Matsuda, Appl. Phys. Lett. 84, 3229 (2004).

${ }^{38}$ F. Bertram, S. Srinivasan, R. Liu, L. Geng, F. Ponce, T. Riemann, J. Christen, S. Tanaka, H. Omiya, and Y. Nakagawa, Mater. Sci. Eng., B 93, 19 (2002).

${ }^{39}$ J. Bruckbauer, P. R. Edwards, T. Wang, and R. W. Martin, Appl. Phys. Lett. 98, 141908 (2011).

${ }^{40}$ Y. E. Gmili, G. Orsal, K. Pantzas, T. Moudakir, S. Sundaram, G. Patriarche, J. Hester, A. Ahaitouf, J. Salvestrini, and A. Ougazzaden, Acta Mater. 61, 6587 (2013).

${ }^{41}$ Y. E. Gmili, G. Orsal, K. Pantzas, A. Ahaitouf, T. Moudakir, S. Gautier, G. Patriarche, D. Troadec, J. P. Salvestrini, and A. Ougazzaden, Opt. Mater. Express 3, 1111 (2013).

${ }^{42}$ D. Holec, P. M. F. J. Costa, M. J. Kappers, and C. J. Humphreys, J. Cryst. Growth 303, 314 (2007).

${ }^{43}$ S. de Sousa Pereira, K. P. O'donnell, and E. J. da Costa Alves, Adv. Funct. Mater. 17, 37 (2007).

${ }^{44}$ S. F. Chichibu, A. Uedono, T. Onuma, B. A. Haskell, A. Chakraborty, T. Koyama, P. T. Fini, S. Keller, S. P. DenBaars, J. S. Speck, U. K. Mishra, S. Nakamura, S. Yamaguchi, S. Kamiyama, H. Amano, I. Akasaki, J. Han, and T. Sota, Nat. Mater. 5, 810 (2006).

${ }^{45}$ C. J. Humphreys, Philos. Mag. 87, 1971 (2007).

${ }^{46}$ A. Rosenauer, T. Mehrtens, K. Muller, K. Gries, M. Schowalter, P. V. Satyam, S. Bley, C. Tessarek, D. Hommel, K. Sebald, M. Seyfried, J. Gutowski, A. Avramescu, K. Engl, and S. Lutgen, Ultramicroscopy 111, 1316 (2011).

${ }^{47}$ C. Parker, J. Roberts, S. Bedair, M. Reed, S. Liu, N. El-Masry, and L. Robins, Appl. Phys. Lett. 75, 2566 (1999).

${ }^{48}$ C. A. Parker, J. C. Roberts, S. M. Bedair, M. J. Reed, S. X. Liu, and N. A. El-Masry, Appl. Phys. Lett. 75, 2776 (1999).

${ }^{49}$ G. Orsal, Y. El Gmili, N. Fressengeas, J. Streque, R. Djerboub, T. Moudakir, S. Sundaram, A. Ougazzaden, and J. P. Salvestrini, Opt. Express 4, 1030 (2014).

${ }^{50}$ Despite the fact that the barriers are made of low-content InGaN, the authors choose to keep referring to them as $\mathrm{GaN}$ barriers throughout the remainder of the article, for the sake of simplicity. 